University of Montana

ScholarWorks at University of Montana

\title{
The Assembly of Ecological Communities Inferred from Taxonomic and Functional Composition
}

\author{
Eric R. Sokol \\ E. F. Benfield \\ Lisa K. Belden \\ H. Maurice Valett \\ maury.valett@umontana.edu
}

Follow this and additional works at: https://scholarworks.umt.edu/biosci_pubs

Part of the Biology Commons

Let us know how access to this document benefits you.

\section{Recommended Citation}

Sokol, Eric R.; Benfield, E. F.; Belden, Lisa K.; and Valett, H. Maurice, "The Assembly of Ecological Communities Inferred from Taxonomic and Functional Composition" (2011). Biological Sciences Faculty Publications. 200.

https://scholarworks.umt.edu/biosci_pubs/200

This Article is brought to you for free and open access by the Biological Sciences at ScholarWorks at University of Montana. It has been accepted for inclusion in Biological Sciences Faculty Publications by an authorized administrator of ScholarWorks at University of Montana. For more information, please contact scholarworks@mso.umt.edu. 


\title{
The Assembly of Ecological Communities Inferred from Taxonomic and Functional Composition
}

\author{
Eric R. Sokol, ${ }^{1, \star}$ E. F. Benfield, ${ }^{1}$ Lisa K. Belden, ${ }^{1}$ and H. Maurice Valett ${ }^{2}$ \\ 1. Department of Biological Sciences, Virginia Polytechnic Institute and State University, Blacksburg, Virginia 24061; 2. Flathead Lake \\ Biological Station, University of Montana, Polson, Montana 59860 \\ Submitted May 19, 2010; Accepted January 28, 2011; Electronically published April 5, 2011 \\ Online enhancement: zip file. Dryad data: http://dx.doi.org/10.5061/dryad.8445.
}

\begin{abstract}
Among-site variation in metacommunities (beta diversity) is typically correlated with the distance separating the sites (spatial lag). This distance decay in similarity pattern has been linked to both niche-based and dispersal-based community assembly hypotheses. Here we show that beta diversity patterns in community composition, when supplemented with functional-trait information, can be used to diagnose assembly processes. First, using simulated data, we show how the relationship between distance decay patterns in taxonomic and functional measures of community composition can be used to predict the influence of a given trait on community assembly. We then use the patterns generated by the simulation as a template to show that the sorting of benthic macroinvertebrate metacommunities in headwater streams is likely influenced by different sets of functional traits at regional and local scales. We suggest that functional-trait databases and spatially referenced taxonomic surveys can be used to predict the spatial scales at which different aspects of interspecific functional variation are involved in nichebased community assembly while accounting for the influence of dispersal-based community assembly processes.
\end{abstract}

Keywords: community assembly, beta diversity, functional traits, macroinvertebrates, headwater streams.

\section{Introduction}

The biogeography of a metacommunity (Leibold et al. 2004) is a product of the interaction between contemporary community assembly processes and historical factors that organize regional biodiversity (Ricklefs 1987; Weiher and Keddy 1999; Gaston 2000; Whittaker et al. 2001; Martiny et al. 2006). Contemporary influences affect the structure and function of assemblages of organisms at different sites in the metacommunity (Whittaker et al. 2001; Allan and Castillo 2007a). For example, a large por-

* Corresponding author. Present address: Florida International University, Biscayne Bay Campus, 3000 NE 151st Street, MSB 352, North Miami, Florida 33181; e-mail: ersokol@fiu.edu.

Am. Nat. 2011. Vol. 177, pp. 630-644. (C) 2011 by The University of Chicago. 0003-0147/2011/17705-52179\$15.00. All rights reserved.

DOI: $10.1086 / 659625$ tion of variation in stream macroinvertebrate communities corresponds to local (i.e., riparian and in-stream) environmental gradients (e.g., Sponseller et al. 2001), and macroinvertebrate communities can respond quickly ( $\sim 1$ year) to disturbances that alter the local habitat (e.g., Gurtz and Wallace 1984). Shifts in community composition over such small time periods are often explained by ecological mechanisms that occur over single-generation timescales, such as dispersal and colonization by ovipositing adults from neighboring watersheds and site selection based on available resources. While contemporary ecological processes can organize among-site variation in community composition (i.e., beta diversity sensu Whittaker 1975), they do so in the context of the regional source pool (i.e., gamma diversity sensu Cody 1975; Ricklefs 1987; Holt 1993; Huston 1999).

Because metacommunity composition is linked to source pool composition, character and predictive models must incorporate an understanding of the historical processes that determine source pool heterogeneity (Ricklefs 1987; Holt 1993). The processes (e.g., speciation, extinction, radiation, and replacement of taxonomic groups) that interact with regional-scale environmental factors (e.g., climate, geophysical processes) over evolutionary timescales to organize the regional source pool (Schluter and Ricklefs 1993; Whittaker et al. 2001) are best assessed with patterns in phylogenetic measures of diversity (Losos 1996; Graham and Fine 2008). However, it is difficult to interpret patterns in phylogenetic diversity when assessing a metacommunity in which different taxonomic and functional groups are sorted at different scales (Graham and Fine 2008). Under these circumstances, variation in taxonomic and functional composition among sites can be assessed in a systematic way, while accounting for regional structure in the source pool, to determine the scales at which different traits are sorted in the metacommunity.

Diversity assessment based solely on taxonomic categorization offers limited insight into the processes re- 
sponsible for extant community composition (Bady et al. 2005). In contrast, trait-based assessment focuses on categorization by functional adaptations and has been used to address controls over community composition (Statzner et al. 1997; Lamouroux et al. 2004; Beche et al. 2006). Here we show how functional-trait information can be used in concert with spatially referenced community composition data to create testable community assembly hypotheses that are complementary to the historical insights gained from analysis of phylogenetic diversity and are more ecologically meaningful than assessments of biogeographic patterns based solely on extant taxonomic composition.

Beta diversity (Whittaker 1975) is a quantitative measure of among-site variation in community composition that summarizes biogeographic patterns and is often used to assess how different factors influence metacommunity structure. Analysis of distance-based measures of beta diversity can be used to address how among-site similarity changes as a function of a spatial or environmental gradient (Legendre et al. 2005; Tuomisto and Ruokolainen 2006), which is a measure of community turnover (fig. 1; Vellend 2001). Community turnover along a spatial gradient is an emergent biogeographic pattern that has been documented as distance decay in community similarity
(Nekola and White 1999). Distance decay refers to a decrease in among-site measures of similarity (inversely related to beta diversity) that corresponds to increasing geographic distance (spatial lag; fig. 1B). Ecological interpretation of distance decay requires understanding the spatial properties of factors that affect local recruitment and organization of regional source pools (Nekola and White 1999; Martiny et al. 2006).

The recruitment process that determines local community composition at a given site can be viewed as a stochastic lottery selection from the source pool (Hubbell 2001; Gravel et al. 2006) or as a deterministic process influenced by local environmental constraints (Chase and Leibold 2003). Stochastic lottery-type selection coupled with dispersal limitation is frequently used to model recruitment in neutral-community models (Bell 2001; Hubbell 2001; Gravel et al. 2006). This type of recruitment is independent of ecological interactions at a given site yet can produce nonrandom biogeographic patterns. Deterministic recruitment models rely on habitat characteristics and local processes that restrict recruitment to a functionally uniform subset of the available source pool (Grime 2006). This subset has a trait set that deems them fit for
A

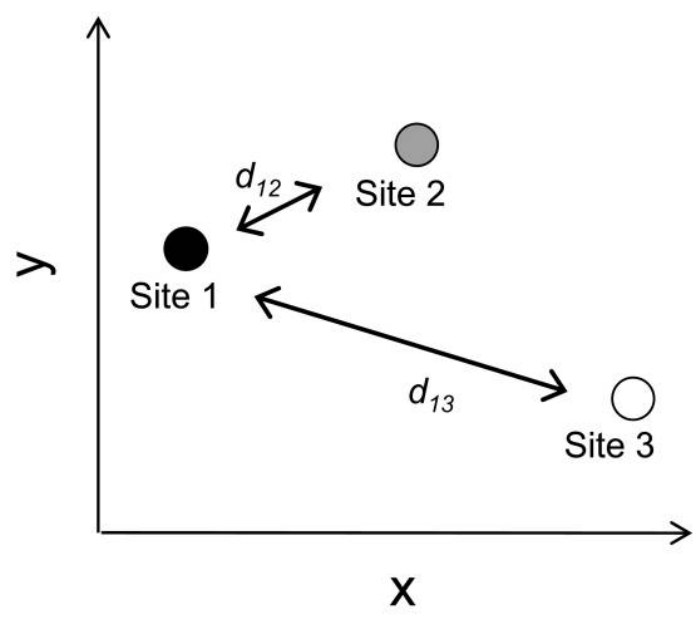

B

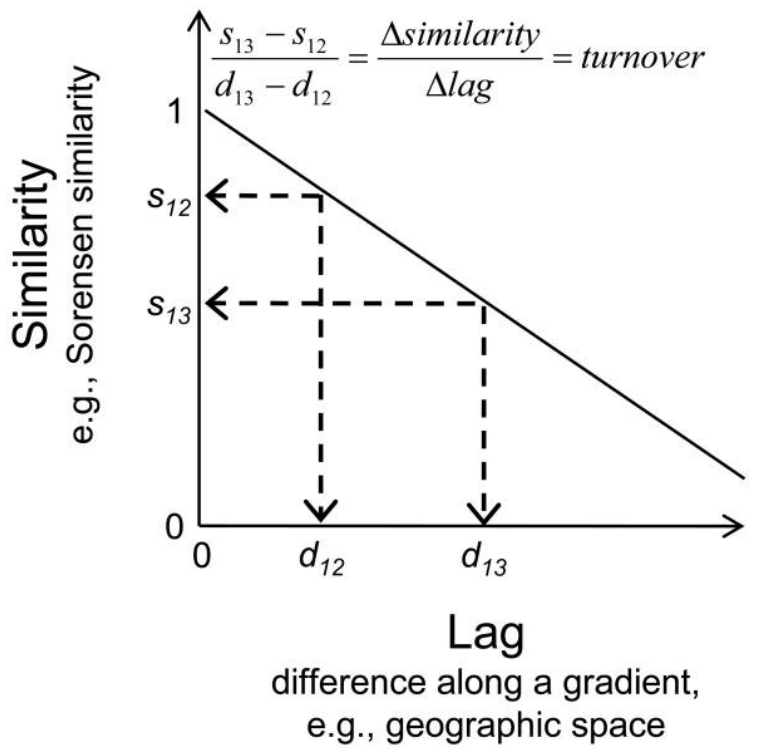

Figure 1: Community turnover defined by distance decay in similarity. $A$, Sites plotted in two-dimensional space, where the $X$ - and $Y$-axes can represent geographic space or the first two axes of an ordination of environmental variables (environmental space). Community composition is represented by shade (similar shade indicates similar community composition). $B$, Pairwise similarity in community composition, $s$ (e.g., Sorensen percent similarity), is calculated as $1-\beta$, where $\beta$ (beta diversity) is quantified with a distance measure (e.g., Bray-Curtis distance). Community turnover is the slope of the distance decay trend line (change in similarity) per unit change in lag. 
sites with specific physiological constraints (Baas Becking 1934; Poff 1997).

A species' set of functional traits determines its fundamental niche (Hutchinson 1957), where it can occur in the landscape relative to the properties of the local habitat, and whether it has an advantage over competitors in those locations. For higher levels of organization (e.g., biogeographic patterns in metacommunities), a species' rank abundance at a given site is a measure of its recruitment success relative to that of interspecific competitors. This serves as an integrative measure of how species compare in their performance rank along each of the $n$ dimensions of niche space that are defined by local habitat characteristics. If neither environmental gradients nor historical factors are relevant, then species' rank abundances remain consistent throughout the metacommunity (Tuomisto and Ruokolainen 2006). Consequential environmental gradients will force a shift in rank abundances and favor different functional types and therefore different taxonomic groups along the gradient (Tuomisto and Ruokolainen 2006), thus producing turnover in the metacommunity.

The structure of the regional source pool determines the local availability of propagules for recruitment at a given site. If dispersal is not limited and all sites effectively share the same source pool, then only environmentally constrained recruitment processes will determine biogeographic patterns (Baas Becking 1934). Provincialism, on the other hand, occurs when the source pools available for local recruitment depend on sites' locations in the landscape. It follows that sites within a province share a similar source pool and sites in separate provinces are colonized by propagules recruited from different source pools. This can occur as either discrete source pool transitions or as a gradient of source pool change across the landscape. When beta diversity is assessed, provincialism describes a metacommunity in which turnover in taxonomic composition occurs within a functional-trait type (i.e., taxonomic composition changes while functional composition stays the same). In this context, "provincialism" should be used as a relative term with respect to a specific functional trait.

Spatially referenced surveys of the taxonomic composition of a metacommunity and taxon-specific functionaltrait data provide the means to identify turnover in functional and taxonomic composition. Here, we have developed a framework to use taxonomic turnover conditional on specific traits (i.e., determine whether change in taxonomic composition corresponds to change in functional composition or whether change in taxonomic composition occurs independently from change in functional composition) as a means to identify which functional attributes are most likely interacting with environmental gradients to sort the metacommunity and to identify the spa- tial scales at which these traits are affected by provincialism. We first outline a set of community assembly hypotheses and their respective predictions for taxonomic and functional-trait turnover patterns. We then use simulated metacommunities under known community assembly scenarios to illustrate how turnover can be used to diagnose community assembly. We apply the diagnostic framework to a data set of benthic macroinvertebrate assemblages to assess the scales at which different functional traits are organized. Last, we compare variation in community composition (taxonomic and functional) against environmental gradients to corroborate inferred relationships between environmental filters and community composition.

\section{Community Assembly Hypotheses and Predictions}

Community assembly models can be categorized by a factorial combination of recruitment type (random lottery [stochastic] or environmentally constrained [deterministic]) and source pool type (provincial or uniform; Tuomisto et al. 2003; Martiny et al. 2006) to yield four general hypotheses (fig. 2). Each hypothesis predicts a unique turnover pattern in community composition that can be

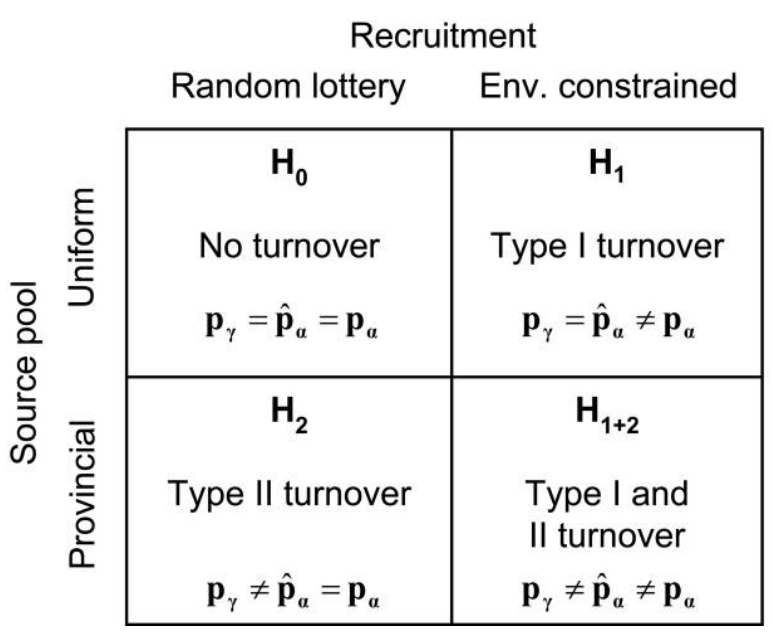

Figure 2: General community assembly hypotheses and predicted turnover patterns for a factorial combination of recruitment and source pool types. $H_{0}$, random-lottery recruitment from a regionally homogenous source pool; $H_{1}$, environmentally constrained recruitment from a regionally homogenous source pool; $H_{2}$, stochastic traitneutral recruitment from provincial source pools; $H_{1+2}$, environmentally constrained recruitment from provincial source pools. Each hypothesis corresponds to a predicted type of turnover in community composition and relationship between regional diversity and local diversity; $\mathbf{p}_{\gamma}, \hat{\mathbf{p}}_{\alpha}$, and $\mathbf{p}_{\alpha}$ are the relative abundances of the regional source pool (gamma diversity), the locally available source pool (expected alpha diversity), and the extant assemblage (observed alpha diversity), respectively. 
expressed as statistically testable equivalence relationships among $\mathbf{p}_{\gamma}, \hat{\mathbf{p}}_{\alpha}$, and $\mathbf{p}_{\alpha}$, which are vectors of relative abundances; $\mathbf{p}_{\gamma}$ is a measure of regional diversity (gamma diversity), $\hat{\mathbf{p}}_{\alpha}$ represents the locally available pool for recruitment at a site (expected alpha diversity), and $\mathbf{p}_{\alpha}$ is the extant community composition at a site (observed alpha diversity).

Further, $H_{0}$ is a null model with random-lottery recruitment from a uniform source pool that predicts no community turnover, and thus, $\mathbf{p}_{\gamma}=\hat{\mathbf{p}}_{\alpha}=\mathbf{p}_{\alpha}$. Failure to reject $H_{0}$ does not indicate that a community is trait neutral (i.e., species have equivalent "fitness" with respect to a given trait; Hubbell 2001); rather, it indicates that processes organizing local diversity and rank abundances uniformly scale up to the region (Tuomisto and Ruokolainen 2006). Under $H_{0}$, if a species has a high regional relative abundance (presumably because it is competitively superior), then it is expected to be more abundant everywhere in the region regardless of environmental variation.

Turnover in community composition can occur along an environmental gradient (type I turnover) or within a functional group (type II turnover, i.e., provincialism; Ackerly and Cornwell 2007). Type I turnover results from environmentally filtered recruitment from a uniform source pool $\left(H_{1}\right)$ and creates a decay in taxonomic similarity with increasing lag in among-site environmental distance. Under type I turnover, the locally available pool $\left(\hat{\mathbf{p}}_{\alpha}\right)$ is a random sample of the regional pool $\left(\mathbf{p}_{\gamma}\right)$ at all sites in the metacommunity, but the local extant community $\left(\mathbf{p}_{\alpha}\right)$ is a nonrandom subset of the locally available pool that is determined by the local habitat constraints at each site. Type II turnover occurs when sites with similar environmental constraints are colonized from different source pools $\left(\mathrm{H}_{2}\right)$; thus, estimates of the locally available pool are different subsets of the regional pool for sites in different provinces. Accordingly, type II turnover can be thought to reflect different species composition within a functional group resulting from provincialism (i.e., taxonomic turnover conditional on functional composition), while type I turnover is the differential representation of distinct functional groups across different local conditions.

Type I and type II turnover are not mutually exclusive patterns and cannot necessarily be separated if an environmental gradient that affects community composition is spatially autocorrelated (Nekola and White 1999); however, we show how some cases of environmentally constrained recruitment from provincial source pools $\left(H_{1+2}\right)$ can be distilled with supplemental information. Under this type of recruitment scenario, we expect taxonomic similarity to correspond to functional similarity (type I turnover) at local (within-province) scales and turnover in taxonomic composition within functional groups (type II turnover) to occur at regional (among-province) scales.
The occurrence of local type I turnover and regional type II turnover should produce a distance decay pattern in the correlation between measures of taxonomic similarity and functional similarity. This type of turnover pattern indicates that a given functional trait affects community sorting at local scales in a provincial metacommunity, where provincial source pools are organized independent of the trait.

\section{Material and Methods}

\section{Community Assembly Simulation}

We simulated the assembly of metacommunities to produce a template of turnover patterns that correspond to the hypotheses described in figure 2 . We used a lottery model (Gravel et al. 2006) to simulate assemblages in a $100 \times 100$-cell landscape, where cells represent local habitat for stream macroinvertebrates. We created six different community assembly scenarios by using the $\mathrm{R}$ statistical environment ( $\mathrm{R}$ Development Core Team 2009; also see app. A, available in a zip file), and each scenario was simulated using 10,000 replicates. In each scenario, a different set of constraints was imposed on recruitment from a regional source pool to local sites based on the assumptions of the hypothesis being tested.

The source pool $\left(\mathbf{p}_{\gamma}\right)$ for each simulation was constructed using an in situ data set (table C2 in app. C, available in Dryad [http://dx.doi.org/10.5061/dryad.8445]) derived for stream macroinvertebrates of the southern Blue Ridge physiographic province. In each simulation, we assigned regional relative abundance values to 94 taxonomic groups based on the observed rank abundance histogram (Preston 1962) for the in situ data set. The resulting vector of 94 relative abundances, $\mathbf{p}_{\gamma}$, was rescaled to sum to 1 and produced realistic distributions of relative abundances in the regional source pool (e.g., fig. A1, available in a zip file).

A functional-trait score for trait $l$ was randomly assigned from the set $\{0,0.25,0.5,0.75,1\}$ to each species in the regional source pool $\left(\mathbf{p}_{\gamma}\right)$ to create a vector of trait scores assigned to column $l$ of matrix $\mathbf{T}$ (only one trait was used in the simulations presented in this study, making $\mathbf{T}$ a onecolumn matrix [vector] for the simulated data sets). In niche-based community assembly simulations, the trait scores determined how different taxonomic groups were affected by the local environmental constraints. Trait scores were also assigned to taxonomic groups in trait-neutral community assembly simulations. We could then compare coincidental patterns in functional composition that occurred when the trait had no influence on community assembly with patterns in community composition that occurred under niche-based scenarios. 
A metacommunity was created in each simulation in the $100 \times 100$-cell landscape by assigning assemblages of $n_{i}$ individuals to 100 randomly selected grid cells, using a lottery process that recruited individuals one at a time. The density $\left(n_{i}\right)$ for each site $i$ was randomly set to one of the observed densities from the in situ data set (table C2). The probability of recruitment $\left(\mathbf{R}_{i, j}\right)$ at site $i$ for species $j$, given its relative abundance in the metacommunity, $\left[\mathbf{p}_{\gamma}\right]_{j}$, was calculated as

$$
\mathbf{R}_{i, j}=\frac{\lambda_{i, j}\left[\mathbf{p}_{\gamma}\right]_{j}}{\sum_{k=1}^{s} \lambda_{i, j}\left[\mathbf{p}_{\gamma}\right]_{j}} .
$$

The interaction between each species' functional characteristics and relevant environmental gradients is described by the survival probability, $\lambda_{i, j}$. The denominator rescales the recruitment probability to the range $[0,1]$ on the basis of the recruitment probabilities of all $s$ species $(s=94)$.

The overall $\lambda_{i, j}$ of species $j$ at site $i$ after accounting for the effect of environmental constraints on all $t$ traits was determined by

$$
\lambda_{i, j}=\prod_{l=1}^{t}\left(1-\mathbf{E}_{i, l}+\mathbf{E}_{i, l} \mathbf{T}_{j, l}\right),
$$

where $\mathbf{E}$ is a site $\times$ environmental constraint matrix. We never simulated more than one environmental constraint $(l)$ at a time, and therefore, $\mathbf{E}$ is a one-column matrix (vector) in all our simulations. The term $\mathbf{E}_{i, l}$ describes the filtering effect at site $i$ by an environmental constraint $l$ on a corresponding trait $l$ in the range $[0,1]$, where 1 indicates maximum filter strength (excluding all individuals susceptible to the filter), and $\mathbf{T}$ is a taxon $\times$ trait matrix of values in the range $[0,1]$, indicating the level of resistance for each taxonomic group $(j)$ to the filtering effect of each environmental constraint $(l)$, where a value of 1 indicates complete resistance to the corresponding constraint. The resulting $\lambda_{i, j}$ is in the range $[0,1]$, where a value of 0 indicates that species $j$ has 0 probability of recruitment at site $i$.

Metacommunities were assembled under six different scenarios (fig. 3; for a graphical representation of the different scenarios, see app. A; for data files and R code necessary to run the simulations, see app. B, available in a zip file). Scenarios $A-C$ simulated recruitment from a uniform regional source pool (i.e., $\mathbf{p}_{\gamma}=\hat{\mathbf{p}}_{\alpha}$ ), and $D-F$ simulated recruitment from two distinct provinces (i.e., $\mathbf{p}_{\gamma} \neq \hat{\mathbf{p}}_{\alpha}$ ) by restricting 25 of the 50 available species to one half of the grid and the other 25 to the other half. We used this discrete partitioning of source pools to represent a simplified case of provincialism for ease of interpretation. Scenario $A$ represents the null model $\left(H_{0}\right)$, in which the assemblage associated with each grid cell is a random sample from the source pool. Community assem- bly in scenario $D\left(\mathrm{H}_{2}\right)$ is also random, but the source pools are provincial. For each hypothesis involving niche-based recruitment $\left(H_{1}\right.$ and $\left.H_{1+2}\right)$, scenarios with spatially independent (local random) and spatially organized (regionalgradient) environmental constraints were created. Local random environmental filters were used in scenarios $B$ $\left(H_{1}\right)$ and $E\left(H_{1+2}\right)$. A local random filter $l$ was simulated by randomly assigning a vector of 100 random filtering intensity values to column $l$ of matrix $\mathbf{E}$ (only one filter was used in the simulation; thus, $\mathbf{E}$ is a one-column matrix [vector] in the simulated data sets) from a normal distribution $(\mu=0.7, \sigma=0.04)$. Regional-gradient environmental filters were modeled in scenarios $C\left(H_{1}\right)$ and $F$ $\left(H_{1+2}\right)$ and increased linearly from a filtering intensity of 0 to 0.9 along the $X$-axis in the landscape. Consequently, the filter effect at a given site in scenarios $C$ and $F$ was a linear function of the site's position in the landscape.

The scenarios described above reflect the different recruitment processes hypothesized in figure 2 , such that scenario $A$ models $H_{0}$, scenarios $B$ and $C$ model $H_{1}$, scenario $D$ models $H_{2}$, and scenarios $E$ and $F$ model $H_{1+2}$. The purpose of simulating these particular community assembly scenarios was to assess whether the expected turnover patterns occurred under simple cases of the hypotheses outlined in figure 2 or whether the expected patterns were obscured by the stochasticity inherent in lottery-type recruitment. There are other, more complex, scenarios that likely occur in real systems. For example, $H_{1+2}$ could include a scenario in which the direction of provinciality is parallel to the direction of the environmental gradient. A simulation of such a scenario might yield interpretable results; however, turnover patterns in this case would be a product of the assumptions used to model the spatial properties of provinces (e.g., perfectly discrete pools) and environmental filters (e.g., perfectly linear gradients). Real data sets are sure to violate at least one of these assumptions; therefore, we do not pursue the parallel case further.

Mantel correlograms were used to summarize turnover patterns in taxonomic and functional composition for each scenario. Mantel statistics and associated $P$ values for correlograms were calculated separately for each replicate in each community assembly scenario. Cutoffs for lag classes (i.e., the between-site distances measured in grid cells used to group pairwise measures of similarity to calculate the Mantel statistic for each spatial lag) were held constant for all simulations so the median and $95 \%$ confidence interval Mantel correlation $\left(r_{\mathrm{M}}\right)$ values could be calculated at each spatial lag for a given community assembly scenario. 


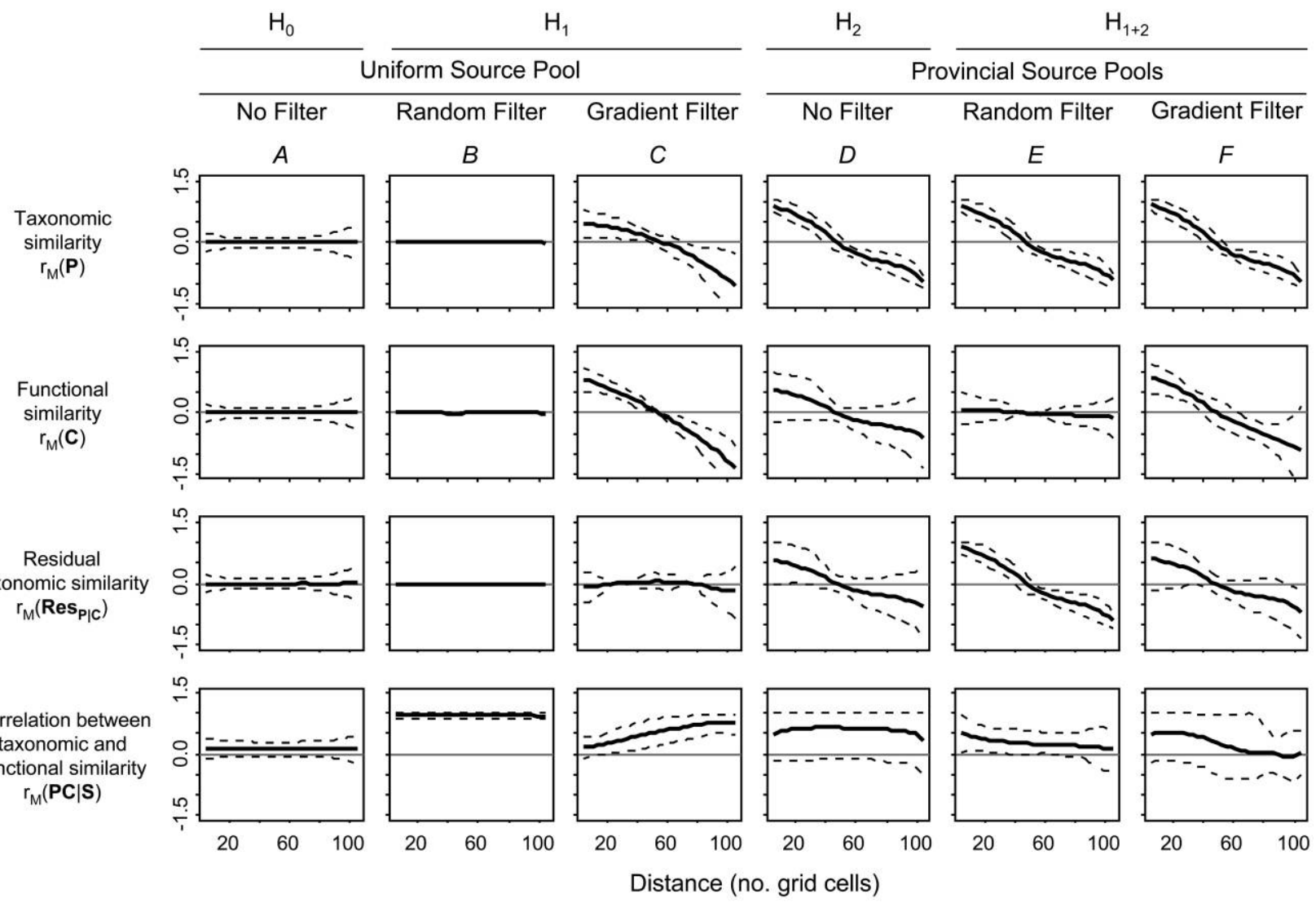

Figure 3: Simulated community turnover patterns. Mantel correlograms of taxonomic similarity $\left(r_{\mathrm{M}}(\mathbf{P})\right)$, functional similarity $\left(r_{\mathrm{M}}(\mathbf{C})\right)$, taxonomic similarity conditional on functional similarity $\left(r_{\mathrm{M}}\left(\operatorname{Res}_{\mathrm{p} \mid \mathrm{C}}\right)\right)$, and the absolute correlation between taxonomic similarity and functional similarity at each spatial lag $\left(r_{\mathrm{M}}(\mathbf{P C} \mid \mathbf{S})\right)$ for six community assembly scenarios (see app. A, available in a zip file). Scenarios $A-$ $C$ recruit from a homogenous regional source pool, and scenarios $D-F$ recruit from provincial regional source pools. $A, H_{0} ; B, H_{1}$ with local random environmental filters; $C, H_{1}$ with a regional-gradient environmental filter; $D, H_{2} ; E$, $H_{1+2}$ with local random environmental filters; $F, H_{1+2}$ with a regional-gradient environmental filter. Each scenario was simulated 10,000 times. Dashed lines indicate $95 \%$ confidence intervals around the mean spatial trend in each Mantel statistic.

\section{Observed Community Composition}

The in situ data set was amassed from 24 observations of aquatic macroinvertebrate assemblages from forested headwater streams (orders 1-3) in the southern Blue Ridge physiographic province. Sites include four watersheds sampled in 2005 in the Nantahala National Forest, North Carolina, as well as macroinvertebrate density data from forested headwater streams from three additional studies in Virginia, Georgia, and North Carolina (Harding et al. 1998; Sponseller et al. 2001; Cook 2003). All sites were geospatially referenced with a handheld GPS or from location estimates by using 7.5' U.S. Geological Survey (USGS) topographic maps using the NAD83 datum (Schwarz 1989; for site information and sampling methods, see table $\mathrm{C} 1$; for observed macroinvertebrate densities, see table C2).
Macroinvertebrate community composition data for each site represent a benthic assemblage from a 50-250$\mathrm{m}$ stream reach. Sites were sampled using area-specific, quantitative sampling methods (e.g., Surber sampler) with a mean sampling effort of 0.098 samples $\mathrm{m}^{-1}$ of stream reach $\left( \pm 0.002\right.$ samples $\left.\mathrm{m}^{-1} \mathrm{SE}\right)$. Only taxonomic groups included in the North American trait database (Poff et al. 2006; Vieira et al. 2006) were used to assess the functional composition of aquatic macroinvertebrate assemblages, excluding the family Chironomidae. Taxonomic data had a genus-level resolution unless trait data were available only at a coarser taxonomic resolution in the trait database. A taxon $\times$ trait score matrix, $\mathbf{T}$ (table C3; for a description of trait scores, see table C4), was modified from the list of taxon-specific trait scores provided by Poff et al. (2006). We scaled all trait scores to a range of $[0,1]$, and categorical 
traits (e.g., functional feeding group, which describes feeding mechanism, and habit, which describes mode of existence and indicates habitat preference; Merritt and Cummins 1996) were scored as a set of binary variables for each category.

\section{Community-Aggregate Functional Composition}

For both simulated and observed (in situ) metacommunity data sets, taxonomic composition was described with a site $\times$ taxonomic group matrix $(\mathbf{P})$ of $\log (x+1)$-transformed relative abundances. A matrix, $\mathbf{C}$, of communityaggregate functional-trait scores (columns) for a set of sites (rows) in a metacommunity was calculated as $\mathbf{C}=\mathbf{P T}^{\prime}$, where $\mathbf{T}^{\prime}$ is the transpose of the taxon $\times$ functional-trait score matrix (T; Lavorel et al. 1999; Statzner et al. 2001; McCune and Grace 2002; Lamouroux et al. 2004; Doledec et al. 2006).

\section{Distance-Dependent Patterns in Community Composition}

Distance decay in community similarity is a pervasive beta diversity pattern in which among-site similarity in taxonomic composition decreases as a function of geographic distance between sites (Nekola and White 1999). In this study we used Mantel correlograms to quantify distance decay patterns in taxonomic similarity. Mantel tests properly account for violations of the assumption of independence among observations that occur when assessing correlations among distance matrixes (Legendre and Legendre 1998; Goslee and Urban 2007; Laliberte 2008). Further, we used correlograms to assess distance decay patterns in functional similarity, taxonomic similarity conditional on functional composition, and the correlation between taxonomic composition and functional composition.

To generate the correlograms necessary to assess distance decay in taxonomic and functional composition, site $\times$ site distance matrixes $\left(\mathbf{D}_{\mathbf{S}}, \mathbf{D}_{\mathrm{P}}\right.$, and $\left.\mathbf{D}_{\mathrm{C}}\right)$ were estimated from spatial coordinates (S), taxonomic composition $(\mathbf{P})$, and community-aggregate functional-trait composition (C) data matrixes, respectively, for simulated and in situ metacommunities. Euclidean distances calculated from a site $\times x, y$ geographic coordinate matrix (S) were used in the distance matrix $\mathbf{D}_{\mathbf{s}}$. The coordinates of $\mathbf{S}$ were quantified in terms of grid cell number for simulated data sets and in terms of Universal Transverse Mercator (UTM) coordinates for the in situ data set. Bray-Curtis distance measures were used to calculate $\mathbf{D}_{\mathbf{P}}$ and $\mathbf{D}_{\mathbf{C}}$ from $\mathbf{P}$ and C, respectively.

Mantel correlograms for taxonomic composition and functional composition were calculated using the ecodist package for R (Goslee and Urban 2007). The Mantel correlation statistic estimated for each spatial lag in a Mantel correlogram $\left(r_{\mathrm{M}}(\mathbf{P})\right.$ for taxonomic similarity, $r_{\mathrm{M}}(\mathbf{C})$ for functional similarity) is a metric of relative similarity. For instance, a high value of $r_{\mathrm{M}}(\mathbf{P})$ indicates that the taxonomic composition of sites is more similar within a spatial lag than among lags (Legendre and Legendre 1998). Significance tests using 10,000 bootstrapped permutations were used to estimate $P$ values for the correlation statistic at each spatial lag.

Correlograms were also used to assess distance-based patterns in the interaction between taxonomic and functional similarity. We used Mantel correlograms calculated from $\operatorname{Res}_{\mathbf{P} \mid \mathrm{C}}$, which is a site $\times$ site matrix of the residuals of a simple linear regression between the elements of $\mathbf{D}_{\mathbf{P}}$ and $\mathbf{D}_{\mathrm{C}}$, to assess change in relative similarity in taxonomic composition as a function of spatial lag after accounting for the correlation between functional and taxonomic similarity. Therefore, distance decay in $r_{\mathrm{M}}\left(\boldsymbol{R e s}_{\mathrm{P} \mid \mathrm{C}}\right)$ is independent of variation associated with a given functional trait. The presence of distance decay in $r_{\mathrm{M}}\left(\boldsymbol{R e s}_{\mathrm{P} \mid \mathrm{C}}\right)$ indicates change in the taxonomic composition of organisms filling a given functional role along a spatial gradient (type II turnover).

We estimated distance decay in the correlation between taxonomic composition and functional composition within each spatial lag class $\left(r_{\mathrm{M}}(\mathbf{P C} \mid \mathbf{S})\right)$ as a second type of assessment of the interaction between taxonomic and functional turnover. We used the ecodist package (Goslee and Urban 2007) to calculate the correlogram for $r_{\mathrm{M}}(\mathbf{P C} \mid \mathbf{S})$, which is the Mantel correlation between subsets of the elements of $\mathbf{D}_{\mathbf{P}}$ and $\mathbf{D}_{\mathbf{C}}$ delineated by lag classes applied to the corresponding geographic distances in $\mathbf{D}_{\mathbf{s}}$. The term $r_{\mathrm{M}}(\mathbf{P C} \mid \mathbf{S})$ is an absolute measure of the relationship between taxonomic composition and functional composition at each spatial lag; therefore, a positive value for $r_{\mathrm{M}}(\mathbf{P C} \mid \mathbf{S})$ indicates type I turnover among sites for the given lag class. Distance decay in $r_{\mathrm{M}}(\mathbf{P C} \mid \mathbf{S})$ occurs when functionally similar sites in close spatial proximity have similar taxonomic composition, but functionally similar sites that are separated by large spatial lags do not share the same taxonomic composition. Thus, distance decay in $r_{\mathrm{M}}(\mathbf{P C} \mid \mathbf{S})$ is a pattern that can result from local type I turnover and regional type II turnover.

For the in situ data set, we plotted these correlograms for each trait and used the distance decay patterns to diagnose the scale at which different traits were sorted in the landscape based on the predictions outlined in figure 2. A trait was classified as regionally sorted if it exhibited turnover patterns predicted under $H_{1}$ (environmental filter acting on a uniform source pool) and as locally sorted if it corresponded with the predictions of $H_{1+2}$ (environmental filter acting on provincial source pools). Traits were not considered candidates for sorting the metacommunity if they exhibited patterns consistent with predictions of $H_{0}$ 
(random recruitment from a uniform source pool) or $\mathrm{H}_{2}$ (random recruitment from a provincial source pool). Subsets of the functional-trait composition matrix, $\mathrm{C}$, were created for regionally $\left(\mathbf{C}_{\text {region }}\right)$ and locally $\left(\mathbf{C}_{\text {local }}\right)$ sorted traits to use as response data matrixes in variance partitioning, using spatial and environmental data matrixes as predictors.

\section{Assessing the Influence of Environmental Gradients}

For functional traits that influence community sorting in the southern Blue Ridge, we expected variation in community composition to correlate with corresponding environmental characteristics. To examine these relationships, we focused on environmental factors that relate to stream power, which is a product of discharge (highly correlated with drainage area) and channel gradient. Stream power predicts the ability of a stream to mobilize and transport material downstream (Lane 1955; Allan and Castillo 2007b). For benthic organisms, stream power is ecologically relevant because it affects habitat structure and stability and can influence resource availability (Montgomery and Buffington 1997; Church 2002; Allan and Castillo 2007b).

We used GRASS GIS, version 6.4.0 (GRASS Development Team 2010), to delineate the watershed for each site and calculate overland flow paths from USGS National Elevation Dataset (NED) maps (Gesch et al. 2002; Gesch 2007) with a $1 / 3^{\prime \prime}$ resolution. Flow accumulation maps were created from NED raster layers, and cells with a $\log$ (accumulation) $>6$ were classified as "stream channel" (Ciolli et al. 2009). Stream gradient for each site was calculated as the mean slope of cells classified as stream channel within the site's drainage area. We controlled for the influence of land use by including only sites located in forested watersheds (mean proportion forest cover for drainage areas, $0.92 \pm 0.02 \mathrm{SE}$ ) in the same physiographic province (southern Blue Ridge). To confirm our assumption that land use was similar at all sites, the National Land Cover data set from 2001 (Homer et al. 2004) was used to estimate the proportion of each drainage area covered by forest (including deciduous, evergreen, and mixed forest types). As expected, given the similarities among the sites, percent forest cover did not explain any variation in community composition and was not included in the final analysis.

To determine the relative contribution of environmental and spatial variation as predictors of among-site variation in taxonomic and functional measures of community composition, we used variance partitioning of raw data matrixes (Borcard et al. 1992; Legendre et al. 2005). The vegan package (Goslee and Urban 2007) for $\mathrm{R}$ was used to calculate adjusted coefficients of determination (Peres-
Neto et al. 2006) for redundancy analyses to determine the proportion of variance in a response data matrix $(\mathbf{Y})$ that was explained by variation in the predictor data matrixes $\mathbf{E}$ and $\mathbf{S}$; $\mathbf{E}$ is a site $\times$ environmental variable matrix $(\log ($ drainage area) and stream gradient), and $\mathbf{S}$ is a matrix describing the spatial structure of the sites (i.e., $x$ and $y$ coordinates defined by the UTM grid). Variance was partitioned for data matrixes describing taxonomic composition $(\mathbf{Y}=\mathbf{P})$, functional composition for locally sorted traits $\left(\mathbf{Y}=\mathbf{C}_{\text {local }}\right)$, and functional composition for traits classified as regionally sorted $\left(\mathbf{Y}=\mathbf{C}_{\text {regional }}\right)$. Partitioning the variance in this manner indicates whether taxonomic $\left(r_{\mathrm{M}}(\mathbf{P})\right)$ and functional $\left(r_{\mathrm{M}}(\mathbf{C})\right)$ distance decay patterns are independent of observed environmental factors $(\mathbf{S} \mid \mathbf{E})$, organized by spatially structured environmental gradients $(\mathbf{E} \cap \mathbf{S})$, or organized by spatially independent environmental factors $(\mathbf{E} \mid \mathbf{S})$.

\section{Results}

\section{Simulated Biogeographic Patterns}

Correlograms used to display distance decay in taxonomic and functional measures of community similarity show that several diagnostic turnover patterns were useful for distinguishing among community assembly scenarios (fig. 3). First, turnover in taxonomic and functional composition was not organized by geographic distance (i.e., no distance decay in relative taxonomic similarity $\left(r_{\mathrm{M}}(\mathbf{P})\right)$ and relative functional similarity $\left(r_{\mathrm{M}}(\mathbf{C})\right)$ when communities were assembled from a uniform source pool under scenarios $A$ (no environmental filter) or $B$ (local environmental filter). However, taxonomic turnover occurred when a regional, spatially organized environmental filter affected recruitment from a uniform source pool (scenario $C)$. Taxonomic turnover was robustly linked to all scenarios with recruitment from provincial source pools $(D-$ $F)$. Functional turnover patterns were evident under conditions of regional environmental gradients $(C$ and $F$ ) irrespective of source pool type. Finally, functional turnover was one of a set of possible outcomes under $D$ and $E$.

Second, turnover in the relative similarity of taxonomic composition conditional on functional composition (distance decay in $r_{\mathrm{M}}\left(\boldsymbol{R e s}_{\mathbf{P} \mid \mathrm{C}}\right)$ ) was apparent only in scenarios with provincial source pools $(D-F)$. The lack of turnover in residual taxonomic similarity $\left(r_{\mathrm{M}}\left(\operatorname{Res}_{\mathrm{P} \mid \mathrm{C}}\right)\right)$ in scenario $C$ suggests that distance decay in taxonomic composition $\left(r_{\mathrm{M}}(\mathbf{P})\right)$ and that in functional composition $\left(r_{\mathrm{M}}(\mathbf{C})\right)$ share a causal origin. For scenario $C$, the shared causal origin is the deterministic effect of the spatially autocorrelated environmental gradient on recruitment (type I turnover) that was built into the community assembly process in the model. Distance decay in residual taxonomic similarity 
$\left(r_{\mathrm{M}}\left(\operatorname{Res}_{\mathrm{P} \mid \mathrm{C}}\right)\right)$ in scenarios $D-F$ indicates that turnover in taxonomic and functional composition occurs along different gradients and/or spatial scales. Turnover with respect to residual taxonomic similarity $\left(r_{\mathrm{M}}\left(\boldsymbol{R e s}_{\mathbf{P} \mid \mathrm{C}}\right)\right)$ was the only outcome observed under scenario $E$, whereas it was a probable but not inevitable outcome under scenarios $D$ and $F$.

Last, the absolute Mantel correlation for spatial lag classes (a positive $r_{\mathrm{M}}(\mathbf{P C} \mid \mathbf{S})$ value indicates type I turnover) was an effective indicator of the scale at which there was a significant correlation between taxonomic and functional composition. While scenario $B$ exhibited no turnover in taxonomic composition $\left(r_{\mathrm{M}}(\mathbf{P})\right)$, functional composition $\left(r_{\mathrm{M}}(\mathbf{C})\right)$, or taxonomic composition conditional on functional composition $\left(r_{\mathrm{M}}\left(\operatorname{Res}_{\mathbf{P} \mid \mathrm{C}}\right)\right)$, it was distinguishable from $A$ by the consistently positive and significant absolute correlation between taxonomic composition and functional composition for pairwise comparisons at all spatial lags $\left(r_{\mathrm{M}}(\mathbf{P C} \mid \mathbf{S}) ; r_{\mathrm{M}} \pm 95 \%\right.$ confidence interval at each spatial lag $>0.75)$. Scenario $C$ also yielded a positive absolute Mantel correlation $\left(r_{\mathrm{M}}(\mathbf{P C} \mid \mathbf{S})\right)$; however, the correlation was weaker for smaller spatial lags because of the innate lack of functional variation among pairwise comparisons of sites in close spatial proximity that were assembled under the influence of a spatially autocorrelated environmental filter.

The Mantel correlation between taxonomic composition and functional composition was more variable in provincial scenarios. Scenario $D$ shows a large amount of variation in this metric over the entire spatial gradient. The spatial trend in scenario $E$ shows a significant positive correlation at local scales and a weak distance decay pattern. Scenario $F$ shows more variability than does scenario $E$ at local scales but suggests a decreasing trend in the correlation at larger spatial lags.

Turnover patterns predicted by the hypotheses in figure 2 occurred in the expected community assembly scenarios. Under the assumption of a homogenous source pool, stochastic (scenario $A$ ) and deterministic (scenarios $B, C$ ) recruitment simulations were distinguishable from each other and yielded the expected turnover patterns. Simulations with provincial source pools (scenarios $D-F$ ) exhibited distance decay in residual taxonomic similarity (fig. $\left.3 ; r_{\mathrm{M}}\left(\operatorname{Res}_{\mathrm{P} \mid \mathrm{C}}\right)\right)$ and thus were distinguishable from scenarios modeling recruitment from uniform source pools. However, stochastic and deterministic community assembly scenarios were not always distinguishable from each other when assemblages were recruited from provincial source pools. The patterns in figure 3 do not provide a template of mutually exclusive diagnostics, but neither do they refute the predictions in figure 2. The variability in some of the distance decay plots demonstrates that the stochasticity inherent in lottery-type recruitment can sometimes ob- scure turnover patterns even under unambiguous community assembly scenarios. However, these turnover patterns do provide some falsifiable predictions for each scenario.

\section{Observed Biogeographic Patterns}

For the in situ data set, a negative correlation between taxonomic similarity and geographic distance for all lag classes pooled $\left(r_{\mathrm{M}}=-0.36, P<.001\right.$; fig. $\left.4 A\right)$ indicates a significant distance decay pattern, and the corresponding correlogram (fig. 4B) provides evidence to reject $H_{0}$. A statistically significant positive correlation between taxonomic composition and functional composition $\left(r_{\mathrm{M}}(\mathbf{P C} \mid \mathbf{S})\right)$ occurs only at spatial lags $<150 \mathrm{~km}$ for a subset of nine of the 27 traits considered in this study (fig. 5C). This subset includes traits related to mobility (Crwl, Drft, Swim), the dominance of collector-gatherer (FFG.CG) and scraper (FFG.SC) functional feeding groups, armoring (Armr), a burrowing habit (Hab.Burrow), development time (Devl), and synchronicity of adult emergence (Sync; see app. C for further trait descriptions). These traits were classified as candidates for organizing community composition at local scales because functional composition correlates with taxonomic composition only at smaller spatial lags. The decay in this correlation at larger spatial lags is an indicator of type II turnover at the regional scale with respect to these traits.

A second subset of nine traits shows distance decay in functional similarity (fig. 5D) and a positive correlation between functional composition and taxonomic composition across the entire study region (fig. $5 F$ ). This subset includes traits related to collector-filtering (FFG.CF), predator (FFG.Pred), and shredder (FFG.SH) functional feeding groups; sprawling (Hab.Sprawl) and clinging (Hab.Cling) habits; body morphology (Shpe); affinity for sites with flowing water (Rheo); adult life span (Life); and voltinism (Volt). These traits were classified as candidates for regional sorting because the correlation between taxonomic composition and functional composition is significantly positive for lag distances spanning the entire spatial scale of the study. The remaining traits did not exhibit distance decay patterns indicative of a scale of sorting and were not classified as locally or regionally sorted.

When community composition is mapped onto the in situ environmental and spatial gradients, physical environmental factors relating to stream power (E, $\log ($ drainage area), and stream gradient) and spatial organization (S, UTM coordinates) explain more among-site variation in functional composition than does taxonomic composition (table 1). Taxonomic composition (P) is weakly organized by geography ( $\mathbf{S}$; adjusted $R^{2}=0.09$, $P=.02$ ) and is more strongly correlated with the physical 

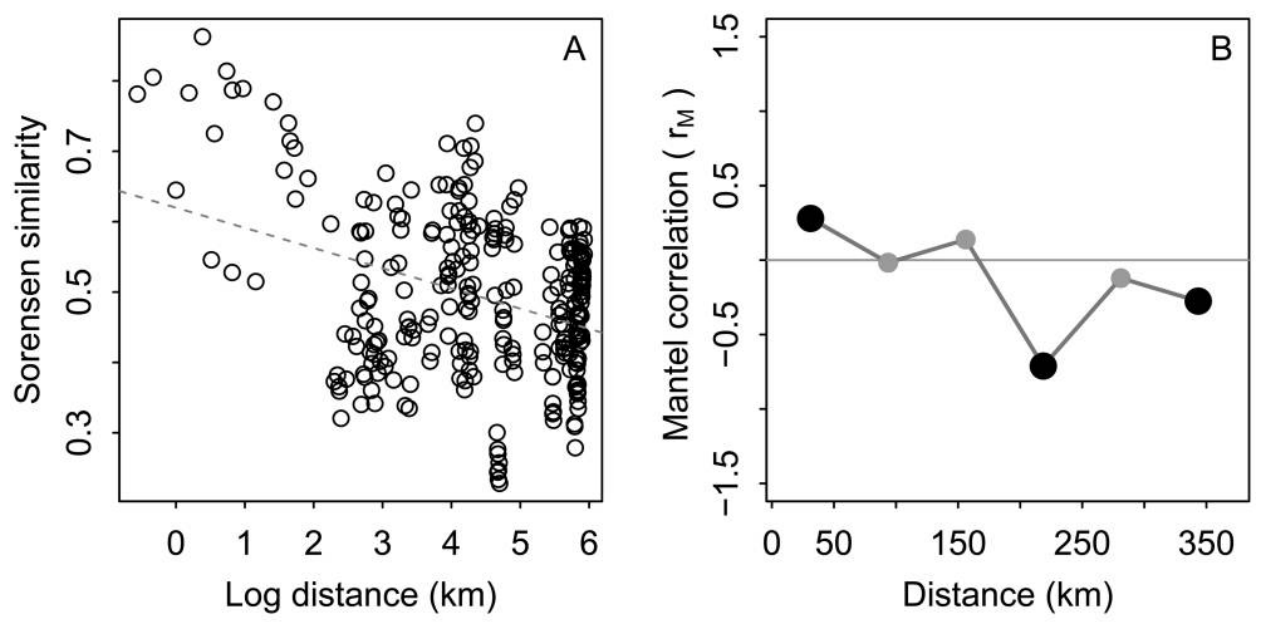

Figure 4: Distance decay in taxonomic similarity for benthic macroinvertebrates in forested headwater streams in the southern Blue Ridge physiographic province. A, Scatterplot of site $\times$ site measures of taxonomic similarity ( $Y$-axis) over log-transformed Euclidean distances in geographic space $\left(X\right.$-axis). Taxonomic similarity is negatively correlated with $\log$ (distance) $\left(r_{\mathrm{M}}=-0.36, P<.001\right)$. The dashed line was fitted with simple linear regression, but the fit statistics are not reported because a Mantel correlation statistic is a more appropriate summary of the correlation between taxonomic similarity ( $Y$-axis) and $\log$ (geographic distance) ( $X$-axis). $B$, Mantel correlogram of taxonomic composition. Black symbols indicate a significant $(P<.05)$ Mantel statistic for that lag class.

habitat (E; adjusted $R^{2}=0.24, P=.01$ ). Community composition with respect to the nine locally sorted traits $\left(\mathbf{C}_{\text {local }}\right)$ is correlated with environmental variation, independent of spatial structure $(\mathbf{E} \mid \mathbf{S})$, whereas community composition with respect to the nine regionally sorted traits $\left(\mathbf{C}_{\text {regional }}\right)$ correlates with spatially organized environmental variation $(\mathbf{E} \cap \mathbf{S})$. Thus, all traits are correlated with variation in the physical environment, but only the nine traits included in $\mathbf{C}_{\text {regional }}$ correlate with a regional gradient in factors relating to stream power.

\section{Discussion}

The classical niche concept posits the untestable hypothesis (Simberloff and Boecklen 1981) that species coexist at a site only if there is an ecologically meaningful difference between them with respect to a functional trait, such that they occupy different areas of niche space within a site (Gause 1934; Hutchinson 1957). Limited connectivity between the source pool and local assemblages (e.g., dispersal-based community assembly) in a stochastic system can provide a trait-neutral and more parsimonious (Hubbell 2005) alternative mechanism to allow species to coexist (Hurtt and Pacala 1995). However, ignoring niche-based assembly would ignore many well-established relationships between environmental complexity and community composition (e.g., MacArthur and MacArthur 1961; Vannote et al. 1980; Poff and Allan 1995).

Our conceptual framework (fig. 2) is analogous to Glea- son's $(1926,1939)$ individualistic concept (IC) for plant communities, in which the composition of a local assemblage is hypothesized to be a product of the interaction between deterministic and stochastic community assembly processes. The similarity among $\mathbf{p}_{\gamma}, \hat{\mathbf{p}}_{\alpha}$, and $\mathbf{p}_{\alpha}$ can be used to assess the relative influence of deterministic recruitment when all pools can be measured independently. Gleason presented arguments for distilling the relative influence of stochastic and deterministic processes in the IC by estimating the locally available source pool at a site $\left(\hat{\mathbf{p}}_{\alpha}\right.$; e.g., from the composition of the seed bank), which can be measured independently from $\mathbf{p}_{\gamma}$ and $\mathbf{p}_{\alpha}$. In a post hoc analysis of a community composition data set, $\hat{\mathbf{p}}_{\alpha}$ cannot be distinguished from $\mathbf{p}_{\gamma}$ and $\mathbf{p}_{\alpha}$; thus, turnover patterns are important because they can be extracted from estimates of $\mathbf{p}_{\gamma}$ and $\mathbf{p}_{\alpha}$ for georeferenced data. The framework we developed starts with the assumption of trait-neutral community assembly and provides a systematic method by which an investigator can use concurrent turnover patterns in taxonomic and functional composition for a given trait as falsifiable predictions without requiring a direct estimate of $\hat{\mathbf{p}}_{\alpha}$. Therefore, comparison of predicted and observed turnover patterns can be used to address the hypothesis that an individual trait influences assembly at a given scale of observation.

The analysis of turnover using distance measures is particularly well suited for addressing how change in similarity can be explained by spatial and environmental gradients (Legendre et al. 2005; Tuomisto and Ruokolainen 2006). 


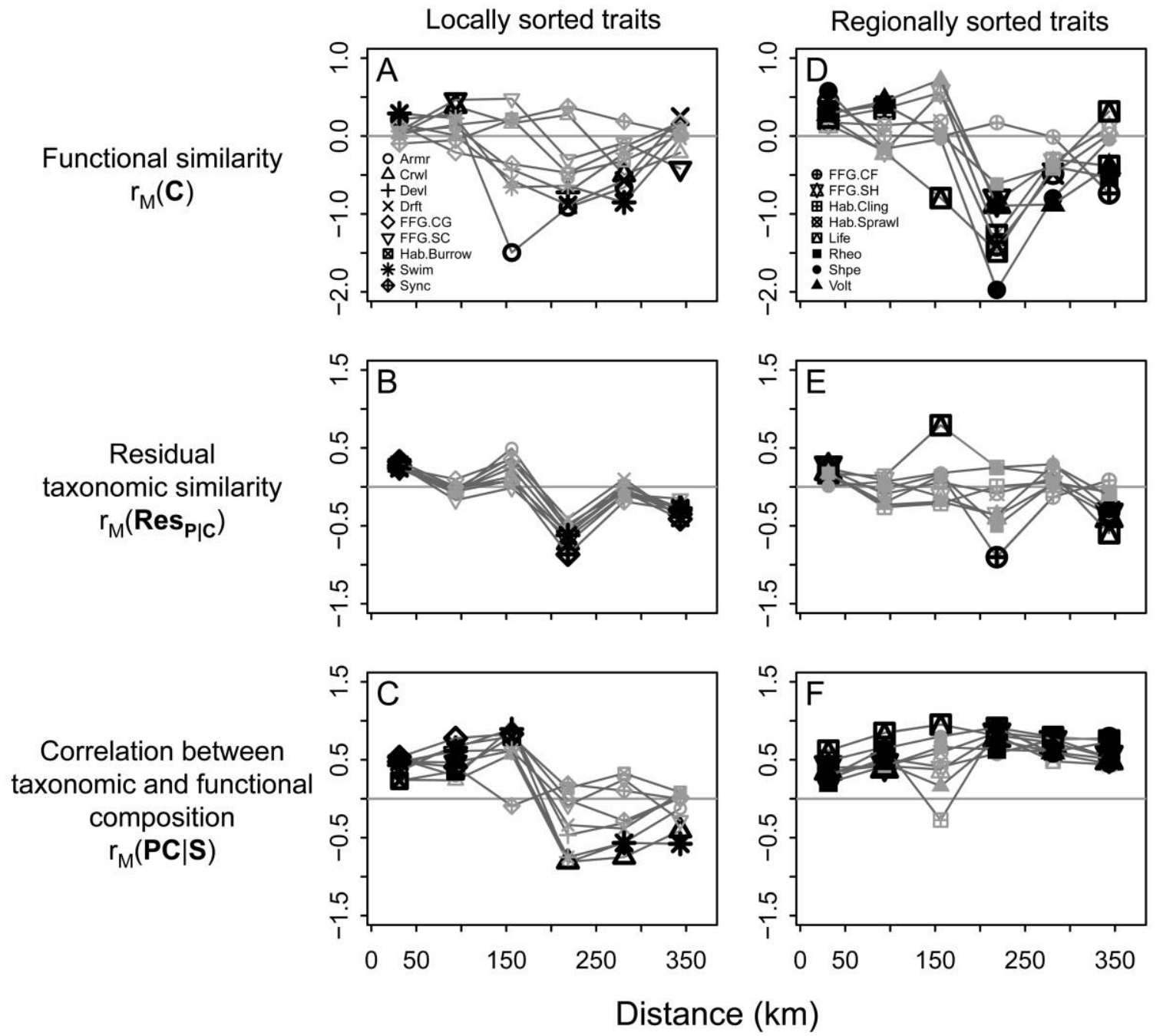

Figure 5: Observed turnover patterns in functional composition and the interaction between taxonomic composition and functional composition for benthic freshwater macroinvertebrate assemblages in forested headwater streams in the southern Blue Ridge physiographic province. Mantel correlograms of functional composition $\left(r_{\mathrm{M}}(\mathbf{C})\right)$, taxonomic composition conditional on functional composition $\left(r_{\mathrm{M}}\left(\boldsymbol{R e s}_{\mathbf{P} \mid \mathbf{C}}\right)\right)$, and the absolute correlation between taxonomic and functional composition at each spatial lag $\left(r_{\mathrm{M}}(\mathbf{P C} \mid \mathbf{S})\right)$. Traits are classified as likely locally sorted or likely regionally sorted based on their distance decay pattern for $r_{\mathrm{M}}(\mathbf{P C} \mid \mathbf{S})$. Large black symbols indicate a significant $(P<.05)$ Mantel statistic for that lag class. For trait code descriptions, see table C4, available in Dryad (http://dx.doi.org/10.5061/dryad.8445).

Distance decay in compositional similarity indicates turnover, but it does not provide enough information to identify turnover type. Distance decay patterns in taxonomic composition, alone, do not allow us to distinguish whether the underlying community assembly mechanism follows $H_{1}$ (deterministic recruitment from a uniform source), $H_{2}$ (stochastic recruitment from a provincial source), or a combination $\left(H_{1+2}\right.$, deterministic recruitment from a provincial source; Nekola and White 1999). By incorporating functional-trait information, investigators can assess the prevalence of type I and type II turnover with respect to each functional trait in a database.
Simulated community assembly scenarios show that it is not possible to construct a dichotomous decision tree for community assembly based on turnover in taxonomic and functional composition because of equifinality (i.e., resultant patterns for different scenarios are not always mutually exclusive). However, our simulations provide a framework of falsifiable predictions that can be used to investigate the mechanisms of community assembly (fig. 2) and can produce an outcome that supports a single general hypothesis in some cases.

The method of investigation presented here is meant to provide an outline for systematically determining a subset 
Table 1: Variance partitioning of observed taxonomic and functional measures of community composition

\begin{tabular}{|c|c|c|c|c|c|c|c|c|c|}
\hline \multirow[b]{2}{*}{ Predictor } & \multicolumn{3}{|c|}{$\mathbf{P}$} & \multicolumn{3}{|c|}{$\mathrm{C}_{\text {local }}$} & \multicolumn{3}{|c|}{$\mathrm{C}_{\text {regional }}$} \\
\hline & Adjusted $R^{2}$ & $P$ & $\mathrm{df}$ & Adjusted $R^{2}$ & $P$ & $\mathrm{df}$ & Adjusted $R^{2}$ & $P$ & df \\
\hline E & .24 & .01 & 2 & .30 & .01 & 2 & .56 & .01 & 2 \\
\hline $\mathrm{E} \mid \mathrm{S}$ & .20 & .01 & 2 & .30 & .01 & 2 & .35 & .01 & 2 \\
\hline$S$ & .09 & .02 & 2 & .04 & .18 & 2 & .22 & .02 & 2 \\
\hline $\mathbf{S} \mid \mathbf{E}$ & .06 & .01 & 2 & .04 & .14 & 2 & .01 & .14 & 2 \\
\hline$E \cap S$ & .03 & NA & 0 & .00 & NA & 0 & .21 & NA & 0 \\
\hline$E \cup S$ & .30 & .01 & 4 & .34 & .01 & 4 & .57 & .01 & 4 \\
\hline
\end{tabular}

Note: $\mathbf{E}$ and $\mathbf{S}$ are data matrixes used as predictors in variance partitioning of community composition data matrixes $\left(\mathbf{P}, \mathbf{C}_{\text {local }}, \mathbf{C}_{\text {regional }}\right)$. $\mathbf{E}$ includes measures of drainage area and mean stream gradient for the watershed delineated for each site. $\mathbf{S}$ contains the spatial coordinates (Universal Transverse Mercator) for each site. $\mathbf{P}$ is a data matrix describing taxonomic composition, $\mathbf{C}_{\text {local }}$ is a data matrix describing community composition using locally sorted traits, and $\mathbf{C}_{\text {regional }}$ is a data matrix describing composition using regionally sorted traits (for traits classified as locally and regionally sorted, see fig. 5 caption). Significance of adjusted $R^{2}$ values (Peres-Neto et al. 2006) was assessed using at most 10,000 permutations. Correlations with $P$ values $<.05$ are in bold. Significance tests could not be performed for correlations for $\mathbf{E} \cap \mathbf{S}$. NA $=$ not available.

from a suite of traits that are most likely involved in metacommunity sorting, as well as the relevant scale. The simulated data sets show that distance decay in taxonomic similarity, alone, precludes scenarios $A\left(H_{0}\right)$ and $B\left(H_{1}\right.$, local filter; fig. 4). Therefore, taxonomic turnover (fig. 4) provides grounds to reject scenarios $A$ and $B$ for the in situ stream macroinvertebrate data set, even though many of the taxonomic groups represented in forested headwater streams have natural ranges that encompass the entire region (Merritt and Cummins 1996).

Three pieces of evidence suggest that the functional composition described in $\mathbf{C}_{\text {regional }}$ is involved in metacommunity sorting along a spatially organized environmental gradient at the regional scale: (1) functional turnover (fig. $5 D$ ) suggests that the traits in $\mathbf{C}_{\text {regional }}$ are spatially organized at the regional level, (2) functional and taxonomic composition are positively correlated at all spatial lags (fig. $5 F$ ), and (3) $\mathbf{C}_{\text {regional }}$ correlates with an environmental gradient (factors relating to stream power; table 1) that spans the extent of the southern Blue Ridge physiographic province. Community sorting at such large spatial and temporal scales invokes historical ecological processes (Whittaker et al. 2001), the mechanisms of which are best assessed using phylogenetic data (Losos 1996; Graham and Fine 2008).

The positive correlation between taxonomic composition and functional composition $\left(r_{\mathrm{M}}(\mathbf{P C} \mid \mathbf{S})\right.$; fig. 5) at small spatial lags is consistent with deterministic sorting of taxonomic groups with respect to the traits included in $\mathbf{C}_{\text {local }}$ at local scales $(<150 \mathrm{~km}$, where study extent is $>350 \mathrm{~km})$. Decay in this correlation statistic at larger spatial lags indicates that the influence of locally sorted traits is confounded by other factors at the regional scale. The ecological interpretation of this decay pattern is that different taxonomic groups are filling the functional roles associated with these traits at sites that are separated by large spatial lags in the metacommunity.

While the observed turnover patterns for traits included in $\mathbf{C}_{\text {local }}$ match predictions for local deterministic sorting from provincial source pools $\left(H_{1+2}\right.$; fig. 2$)$ and the corresponding simulated patterns (fig. $3 E, 3 F$ ), the simulated data set also shows that similar spurious turnover patterns in functional composition can occur even when no environmental filter is interacting with the traits (fig. 3D). However, the correlation between $\mathbf{C}_{\text {local }}$ and environmental variation that is independent of spatial structure $(\mathrm{E} \mid \mathrm{S}$; table 1) lends corroborating support to hypotheses consistent with deterministic sorting (scenarios $E$ and $F$ ). Thus, the relationship between these traits and the environment is consistent throughout the region, but the gradient is not spatially structured and there is no spatial structure to the variation in functional composition with respect to these traits.

This inferential framework applied to functional traits could be used with site-specific measures of habitat characteristics instead of functional traits (e.g., replace the trait score data matrix $\mathbf{C}$ with the environmental data matrix E when calculating the correlograms), but we chose to outline a process for using functional composition for several reasons. First, functional-trait data can be mapped across sites at the same scale at which the community is observed; thus, functional turnover patterns are a direct indication of the scale at which an associated environmental filter is affecting community assembly. Second, if a functional-trait database is available, then it is universally applicable to any community composition data set, assuming that intraspecific variability with respect to the trait is negligible relative to interspecific differences. Last, assessing patterns in functional composition should help 
refine the list of potential environmental gradients to assess as filters that affect community assembly.

An often-ignored influence on community assembly is the effect of the observational scale of a study on the perceived relevance of the processes hypothesized to be organizing a metacommunity (Nekola and White 1999). The spatial lag at which functional turnover occurs indicates the scale at which the associated environmental filter affects community sorting and the observational grain size for which the filter would be considered "local." The scale of provincialism in the regional source pool can be estimated with the spatial lag at which taxonomic turnover conditional on functional composition transitions from positive to either nonsignificant or negative. Such turnover patterns can also be used to interpret the order of hierarchical environmental filters (Tonn et al. 1990; Poff 1997). For example, the in situ data set suggests that trait. such as rheophilic preference (favoring habitats with flowing water) and body morphology (among others in $\mathbf{C}_{\text {region }}$ ) sort the metacommunity regionally and determine the local source pools from which propagules are recruited at a site based on the traits in $\mathbf{C}_{\text {local }}$.

When used without phylogenetic data, the analysis of turnover patterns is best applied to detect which environmental filters and functional traits interact to affect community structure (Schluter and Ricklefs 1993; Losos 1996). This type of analysis is useful when trying to select candidates from a set of traits and for identifying when a trai ${ }^{\perp}$ is relevant to sorting at a regional scale but is confounded by provincial source pools that were organized by historical factors. Recently developed analyses using phylogenetic beta diversity (PBD; Graham and Fine 2008; Graham et al. 2009; Vamosi et al. 2009) are more appropriate for assessing how historical factors, such as dispersal, speciation, and extinction events, have structured source pools $\rightarrow$ However, PBD-based analyses are difficult to interpre $\rightarrow$ when assessing taxonomically diverse assemblages in which different species respond to environmental gradients occurring at different spatial scales (Graham and Fine 2008). Thus, using the framework presented here witl classic measures of community composition (i.e., measures of relative abundances of different species) can narrow the focus to subsets of assemblages for which PBD can then be used to assess ultimate factors affecting community composition. The utility of our approach is in its ability to identify the factors that likely affect contemporary recruitment processes and how recruitment functions in the context of the regional source pool. Such information can be used to predict diversity patterns at neighboring siter or the immediate response of communities in the wake of disturbance.

\section{Acknowledgments}

We would like to thank J. M. Hoch, R. H. Jones, J. C. Trexler, J. R. Voshell Jr., and two anonymous reviewers for their helpful feedback on this manuscript. This work was supported by the National Science Foundation Ecosystems Program (DEB0425642), the Coweeta Hydrologic Laboratory Long Term Ecological Research Program (NSF-DEB 9632854), the U.S. Forest Service (04-CA-11330139-164, 03-CA-11330139-202), the Virginia Academy of Science, the Graduate Research Development Program at Virginia Tech, and the President's Award from the North American Benthological Society.

\section{Literature Cited}

Ackerly, D. D., and W. K. Cornwell. 2007. A trait-based approach to community assembly: partitioning of species trait values into within- and among-community components. Ecology Letters 10: 135-145.

Allan, J. D., and M. M. Castillo. 2007a. Community assembly is determined by species pool, habitat sorting, and species interactions. Pages 362-364 in J. D. Allan and M. M. Castillo, eds. Stream ecology: structure and function of running waters. Springer, Dordrecht.

_ eds. 2007b. Stream ecology: structure and function of running waters. Springer, Dordrecht.

Baas Becking, L. G. M. 1934. Geobiologie of inleiding tot de milieukunde. W. P. Van Stockum \& Zoon, The Hague.

Bady, P., S. Doledec, C. Fesl, S. Gayraud, M. Bacchi, and F. Scholl. 2005. Use of invertebrate traits for the biomonitoring of European large rivers: the effects of sampling effort on genus richness and functional diversity. Freshwater Biology 50:159-173.

$\rightarrow$ Beche, L. A., E. P. McElravy, and V. H. Resh. 2006. Long-term seasonal variation in the biological traits of benthic-macroinvertebrates in two Mediterranean-climate streams in California, USA. Freshwater Biology 51:56-75.

Bell, G. 2001. Ecology: neutral macroecology. Science 293:2413-2418. Borcard, D., P. Legendre, and P. Drapeau. 1992. Partialling out the spatial component of ecological variation. Ecology 73:1045-1055.

Chase, J. M., and M. A. Leibold. 2003. Ecological niches: linking classical and contemporary approaches. University of Chicago Press, Chicago.

Church, M. 2002. Geomorphic thresholds in riverine landscapes. Freshwater Biology 47:541-557.

Ciolli, M., C. Tattoni, A. Vitti, P. Zatelli, and F. Zottele. 2009. GRASS tutorial, version 6.4.0 2010.06.30. University of Trento, Trento.

Cody, M. L. 1975. Towards a theory of continental species diversities: bird distributions over Mediterranean habitat gradients. Pages 214-257 in M. L. Cody and J. M. Diamond, eds. Ecology and evolution of communities. Belknap, Cambridge, MA.

Cook, K. R. 2003. Livestock exclusion effects on the structure and function of headwater streams. MS thesis. Virginia Polytechnic Institute and State University, Blacksburg.

Doledec, S., N. Phillips, M. Scarsbrook, R. H. Riley, and C. R. Townsend. 2006. Comparison of structural and functional approaches to determining landuse effects on grassland stream invertebrate 
communities. Journal of the North American Benthological Society 25:44-60.

$\rightarrow$ Gaston, K. J. 2000. Global patterns in biodiversity. Nature 405:220- $\rightarrow$ 227.

Gause, G. F. 1934. The struggle for existence. Hafner, New York. $\rightarrow$ Gesch, D., M. Oimoen, S. Greenlee, C. Nelson, M. Steuck, and D. Tyler. 2002. The National Elevation Dataset. Photogrammetric Engineering and Remote Sensing 68:5-11.

Gesch, D. B. 2007. The National Elevation Dataset. Pages 99-118 in D. Maune, ed. Digital elevation model technologies and applications: the DEM users' manual. American Society for Photogram metry and Remote Sensing, Bethesda, MD.

$\rightarrow$ Gleason, H. A. 1926. The individualistic concept of the plant succession. Bulletin of the Torrey Botanical Club 53:7-26.

$\rightarrow$. 1939. The individualistic concept of the plant association. American Midland Naturalist 21:92-110.

Goslee, S., and D. Urban. 2007. The ecodist package for dissimilaritybased analysis of ecological data. Journal of Statistical Software 22: $1-19$.

$\rightarrow$ Graham, C. H., and P. V. A. Fine. 2008. Phylogenetic beta diversity: linking ecological and evolutionary processes across space in time. Ecology Letters 11:1265-1277.

$\rightarrow$ Graham, C. H., J. L. Parra, C. Rahbek, and J. A. McGuire. 2009 Phylogenetic structure in tropical hummingbird communities. Proceedings of the National Academy of Sciences of the USA 106. 19673-19678.

GRASS Development Team. 2010. Geographic Resource Analysi Support System (GRASS) software, version 6.4.0. http:// grass.osgeo.org.

$\rightarrow$ Gravel, D., C. D. Canham, M. Beaudet, and C. Messier. 2006. Reconciling niche and neutrality: the continuum hypothesis. Ecology Letters 9:399-409.

$\rightarrow$ Grime, J. P. 2006. Trait convergence and trait divergence in herbaceous plant communities: mechanisms and consequences. Journal of Vegetation Science 17:255-260.

$\rightarrow$ Gurtz, M. E., and J. B. Wallace. 1984. Substrate-mediated response of stream invertebrates to disturbance. Ecology 65:1556-1569.

$\rightarrow$ Harding, J. S., E. F. Benfield, P. V. Bolstad, G. S. Helfman, and E. B D. Jones. 1998. Stream biodiversity: the ghost of land use past. Proceedings of the National Academy of Sciences of the USA 95: 14843-14847.

Holt, R. D. 1993. Ecology at the mesoscale: the influence of regiona processes on local communities. Pages $77-88$ in R. E. Ricklefs and D. Schluter, eds. Species diversity in ecological communities: historical and geographical perspectives. University of Chicago Press, Chicago.

Homer, C., C. Huang, L. Yang, B. Wylie, and M. Coan. 2004. Development of a 2001 national landcover database for the Unitec States. Photogrammetric Engineering and Remote Sensing 70:829840 .

Hubbell, S. P. 2001. A unified theory of biodiversity and biogeog raphy. Princeton University Press, Princeton, NJ.

$\rightarrow-$ 2005. Neutral theory in community ecology and the hypothesis of functional equivalence. Functional Ecology 19:166-172.

$\rightarrow$ Hurtt, G. C., and S. W. Pacala. 1995. The consequences of recruitment limitation: reconciling chance, history and competitive difference between plants. Journal of Theoretical Biology 176:1-12.

$\rightarrow$ Huston, M. A. 1999. Local processes and regional patterns: appropriate scales for understanding variation in the diversity of plants and animals. Oikos 86:393-401.
Hutchinson, G. E. 1957. Concluding remarks. Cold Spring Harbor Symposia on Quantitative Biology 22:415-427.

Laliberte, E. 2008. Analyzing or explaining beta diversity? comment. Ecology 89:3232-3237.

Lamouroux, M., S. Doledec, and S. Gayraud. 2004. Biological traits of stream macroinvertebrate communities: effects of microhabitat, reach, and basin filters. Journal of the North American Benthological Society 23:449-466.

Lane, E. W. 1955. Design of stable alluvial channels. Transactions of the American Society of Civil Engineers 120:1234-1260.

Lavorel, S., S. McIntyre, and K. Grigulis. 1999. Plant response to disturbance in a Mediterranean grassland: how many functional groups? Journal of Vegetation Science 10:661-672.

Legendre, P., and L. Legendre. 1998. Numerical ecology. Elsevier, Amsterdam.

Legendre, P., D. Borcard, and P. R. Peres-Neto. 2005. Analyzing beta diversity: partitioning the spatial variation of community composition data. Ecological Monographs 75:435-450.

$\rightarrow$ Leibold, M. A., M. Holyoak, N. Mouquet, P. Amarasekare, J. M. Chase, M. F. Hoopes, R. D. Holt, et al. 2004. The metacommunity concept: a framework for multi-scale community ecology. Ecology Letters 7:601-613.

Losos, J. B. 1996. Phylogenetic perspectives on community ecology. Ecology 77:1344-1354.

$\rightarrow$ MacArthur, R. H., and J. W. MacArthur. 1961. On bird species diversity. Ecology 42:594-598.

Martiny, J. B. H., B. J. M. Bohannan, J. H. Brown, R. K. Colwell, J. A. Fuhrman, J. L. Green, M. C. Horner-Devine, et al. 2006. Microbial biogeography: putting microorganisms on the map. Nature Reviews Microbiology 4:102-112.

McCune, B., and J. B. Grace. 2002. Analysis of ecological communities. MjM Software Design, Gleneden Beach, OR.

Merritt, R. W., and K. W. Cummins. 1996. An introduction to the aquatic insects of North America. Kendall/Hunt, Dubuque, IA.

$\rightarrow$ Montgomery, D. R., and J. M. Buffington. 1997. Channel-reach morphology in mountain drainage basins. Bulletin of the Geological Society of America 109:596-611.

Nekola, J. C., and P. S. White. 1999. The distance decay of similarity in biogeography and ecology. Journal of Biogeography 26:867878.

$\rightarrow$ Peres-Neto, P. R., P. Legendre, S. Dray, and D. Borcard. 2006. Variation partitioning of species data matrices: estimation and comparison of fractions. Ecology 87:2614-2625.

Poff, N. L. 1997. Landscape filters and species traits: towards mechanistic understanding and prediction in stream ecology. Journal of the North American Benthological Society 16:391-409.

Poff, N. L., and J. D. Allan. 1995. Functional-organization of stream fish assemblages in relation to hydrological variability. Ecology 76: 606-627.

$\rightarrow$ Poff, N. L., J. D. Olden, N. K. M. Vieira, D. S. Finn, M. P. Simmons, and B. C. Kondratieff. 2006. Functional trait niches of North American lotic insects: trait-based ecological applications in light of phylogenetic relationships. Journal of the North American Benthological Society 25:730-755.

$\rightarrow$ Preston, F. W. 1962. The canonical distribution of commonness and rarity. I. Ecology 43:185-215.

R Development Core Team. 2009. R: a language and environment for statistical computing. R Foundation for Statistical Computing, Vienna. 
Ricklefs, R. E. 1987. Community diversity: relative roles of local and regional processes. Science 235:167-171.

Schluter, D., and R. E. Ricklefs. 1993. Convergence and the regionacomponent of species diversity. Pages 230-240 in R. E. Ricklefs and D. Schluter, eds. Species diversity in ecological communities: historical and geographical perspectives. University of Chicago Press, Chicago.

Schwarz, C. R. 1989. North American datum of 1983. NOAA Professional Paper NOS 2. U.S. Department of Commerce, National Oceanic and Atmospheric Administration, Silver Spring, MD.

$\rightarrow$ Simberloff, D., and W. Boecklen. 1981. Santa Rosalia reconsidered. size ratios and competition. Evolution 35:1206-1228.

$\rightarrow$ Sponseller, R. A., E. F. Benfield, and H. M. Valett. 2001. Relationships between land use, spatial scale and stream macroinvertebrate communities. Freshwater Biology 46:1409-1424.

$\rightarrow$ Statzner, B., K. Hoppenhaus, M. F. Arens, and P. Richoux. 1997. Reproductive traits, habitat use and templet theory: a synthesis of world-wide data on aquatic insects. Freshwater Biology 38:109135.

$\rightarrow$ Statzner, B., B. Bis, S. Doledec, and P. Usseglio-Polatera. 2001. Perspectives for biomonitoring at large spatial scales: a unified measure for the functional composition on invertebrate communities in European running waters. Basic and Applied Ecology 2:73-85.

$\rightarrow$ Tonn, W. M., J. J. Magnuson, M. Rask, and J. Toivonen. 1990. Intercontinental comparison of small-lake fish assemblages: the balance between local and regional processes. American Naturalist 136:345-375.

$\rightarrow$ Tuomisto, H., and K. Ruokolainen. 2006. Analyzing or explaining beta diversity? understanding the targets of different methods of analysis. Ecology 87:2697-2708.

Tuomisto, H., K. Ruokolainen, and M. Yli-Halla. 2003. Dispersal, environment, and floristic variation of western amazonian forests. Science 299:241-244.

$\rightarrow$ Vamosi, S. M., S. B. Heard, J. C. Vamosi, and C. O. Webb. 2009. Emerging patterns in the comparative analysis of phylogenetic community structure. Molecular Ecology 18:572-592.

$\rightarrow$ Vannote, R. L., G. W. Minshall, K. W. Cummins, J. J. Sedell, and C. E. Cushing. 1980. The river continuum concept. Canadian Journal of Fisheries and Aquatic Sciences 37:130-137.

Vellend, M. 2001. Do commonly used indices of $\beta$-diversity measure species turnover? Journal of Vegetation Science 12:545-552.

Vieira, N. K. M., N. L. Poff, D. M. Carlisle, S. R. Moulton II, M. L. Koski, and B. C. Kondratieff. 2006. A database of lotic invertebrate traits for North America. U.S. Geological Survey Data Series 187, http://pubs.usgs.gov/ds/ds187/pdf/ds187.pdf.

Weiher, E., and P. A. Keddy. 1999. Assembly rules as general constraints on community composition. Pages 3-9 in E. Weiher and P. A. Keddy, eds. Ecological assembly rules. Cambridge University Press, Cambridge.

Whittaker, R. H. 1975. Communities and ecosystems. Macmillan, New York.

$\rightarrow$ Whittaker, R. J., K. J. Willis, and R. Field. 2001. Scale and species richness: towards a general, hierarchical theory of species diversity. Journal of Biogeography 28:453-470.

Associate Editor: Stephen B. Heard Editor: Mark A. McPeek

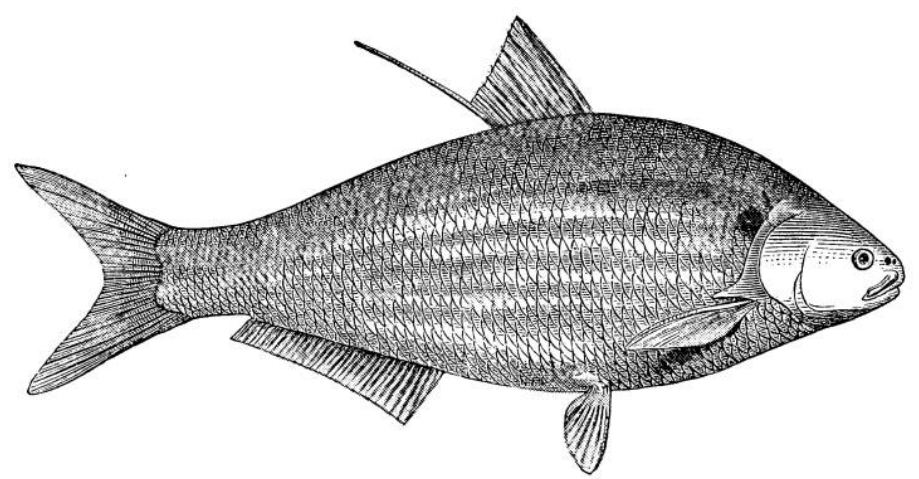

Gizzard shad, Dorosoma cepedianum. From "Notes on Fresh-Water Fishes of New Jersey” by Charles C. Abbott (American Naturalist, 1870, 4:99-117). 